\title{
Entre la ferocidad y el aburrimiento: Un acercamiento al cuento "Las Fieras", de Roberto Arlt
}

Por: Br. Mariela Romero Zúñiga, ITCR ${ }^{1}$

Recibido: 8 de enero, 2016.

Aceptado: 25 de abril, 2016.

\section{RESUMEN}

Este artículo analiza el cuento "Las fieras", del argentino Roberto Arlt, como producto final de una investigación académica dirigida por el sistema de posgrado de literatura latinoamericana de la Universidad de Costa Rica. Se llevó a cabo un estudio de los diversos recursos estilísticos que este autor emplea para deconstruir la imagen de la sociedad bonaerense de los años 30: lenguaje, abordaje de una temática marginal, juego de oposiciones. Los principales aspectos analizados son el ingreso en el lumpen, silencio como lenguaje, lumpen como despojo de la máscara y condición de las mujeres en el lumpen.

\section{ABSTRACT}

\section{BETWEEN FEROCITY AND BOREDOM: AN APPROACH TO THE SHORT STORY “LAS FIERAS", BY ROBERTO ARLT}

This paper is an analysis of the short story "Las fieras", by the Argentinean author Roberto Arlt, as a result of academic research in the postgraduate program in Latin American Literature of the Universidad de Costa Rica. The stylistic resources which this author uses to deconstruct the image of the Buenos Aires society of the 30's, the approach of a marginal theme, and play of opposites are studied. The main analyzed aspects are the becoming part of the lumpen (underclass), silence as language, the lumpen as the removal of masks and the situation of women in the lumpen. noamericana, en la Universidad de Costa Rica. Trabaja como editora técnica en el Instituto Tecnológico de Costa Rica. Contacto: mromero@itcr.ac.cr 
"Me hubiera gustado ofrecerte una novela amable como una nube sonrosada, pero quizás nunca escribiré obra semejante. De allí, que te dedique este libro trabajado por las calles oscuras y parajes taciturnos, en contacto con gente terrestre, triste y somnolienta. Te ruego que lo recibas como una prueba del grande amor que te tengo". A mi esposa Carmen Antinucci de Roberto Arlt.

\section{Dedicatoria de la obra El jorobadito y otros cuentos}

El hombre nace libre pero vive encadenado. En realidad la diferencia es que el salvaje vive en sí mismo, mientras que el hombre social, siempre fuera de sí, no sabe vivir más que en la opinión de los demás, y de ese juicio deduce el sentimiento de su propia existencia.

\section{Jean Jacques Rousseau. El Contrato Social}

\section{INTRODUCCIÓN}

Tras casi cien años desde su aparición en la escena literaria latinoamericana, es posible afirmar que las vanguardias constituyeron una base fundamental sobre la cual se forjó gran parte de la literatura que actualmente es reconocida a nivel mundial. Además, las vanguardias se convirtieron en un importante espacio para la manifestación de las diversas realidades que se desarrollaron a lo largo del continente, de acuerdo con los múltiples contextos donde se llevaron a cabo, así como con las perspectivas desde las cuales se abordó cada una de las temáticas tratadas.

De esta manera, con base en preocupaciones propias de su época (consecuencias de la Primera Guerra Mundial, ideología del progreso, capitalismo, auge de la tecnología, desarrollo de las metrópolis, entre otras), sumado al deseo vehemente de manifestarse en contra de las normas establecidas y la necesidad de darles un nuevo aire a las temáticas y estilos para escribir, este "mosaico de paradojas", como les Ilamó Bosi (2002), se dio a la tarea de ejercer la libertad en el quehacer literario e imponer su propio estilo y perspectiva de vida, los cuales plasmaron de diferentes maneras en los distintos textos.
Uno de los países donde la producción vanguardista tuvo un importante desarrollo fue Argentina. En medio de los múltiples conflictos políticos, sociales, culturales y económicos que se llevaron a cabo en ese país, ligado al crecimiento y ebullición de la ciudad de Buenos Aires, se fue llevando a cabo una especie de collage en donde confluyeron diversas culturas inmigrantes, personas locales que buscaban crecimiento personal y nacional desde diferentes perspectivas, distintos movimientos artísticos, incipientes manifestaciones culturales que encerraban críticas a su entorno, o bien, servían como medio para expresar los diferentes e incluso contradictorios rostros de una misma ciudad.

En el núcleo de la majestuosa y presuntuosamente europea Buenos Aires, desde la arista más oscura, desafiante, apartada y casi desapercibida de esa ciudad de los años treinta, en medio de binarismos, conflictos existenciales y la cruda otredad, Roberto Arlt va más allá de su faceta periodística para convertir lo que una vez quizá fue un reportaje de la nota roja del periódico en un extracto literario que transporta al público lector directamente al bar Ambos Mundos, ese lugar donde la marginalidad y la violencia son parte de la cotidianidad, y el lumpen constituye una caída libre en la cual es posible descender durante el transcurso de la historia del protagonista.

Por lo tanto, el presente trabajo pretende abordar el cuento Las fieras, de este autor argentino, a partir de los mecanismos estilísticos con los cuales se encarga de realizar una clara deconstrucción de la imagen de la sociedad bonaerense que en los años 30 estaba en ascenso debido a una fuerte influencia europea y a un reconocimiento cada vez mayor a escala internacional. De esta manera, Arlt hace uso de elementos como el lenguaje y los pares binarios para poner de manifiesto una problemática que va más allá de un sector social, sino que cala en lo profundo de la existencia de cada uno de los habitantes del lumpen. El análisis se llevará a cabo con base en cuatro aspectos diferentes: entrada en el lumpen, el silencio como lenguaje, la ferocidad como desprendimiento de una máscara, y las mujeres que habitan el lumpen. 
Este texto tan propio de la narrativa arltiana, al igual que el resto de la literatura vanguardista, presenta características diferenciadas por las cuales ha logrado ocupar un lugar privilegiado y ha sido fuente de inspiración para importantes autores posteriores.

\section{“LAS FIERAS”: INGRESO EN EL LUMPEN}

"Las fieras" es un relato perteneciente a la obra EI jorobadito y otros cuentos, publicada en 1933. Inicialmente, el texto pareciera constituir una conversación entre un hombre y una mujer, quien escucha en silencio a su interlocutor hablarle de hechos propios de su cotidianidad. Sin embargo, y como parte del innovador estilo que Roberto Arlt impregnó a lo largo de su obra, se trata de un monólogo en el cual el personaje protagonista, un hombre cuyo nombre se desconoce, realiza una confesión autocompasiva en primera persona, en torno a la condición en que se halla sumergido.

Si bien no hay duda de que en su monólogo hay comentarios directos hacia una mujer que en el pasado desempeñó un rol fundamental en su vida (es posible inferir que quizá fuera su pareja), el discurso se desarrolla de forma introspectiva y a modo de pesimista cavilación. Aunque durante el transcurso del relato se llegue a pensar que en cualquier momento el personaje revelará el misterio que carga y abrirá su pasado a quien lee, la primera frase del cuento se encarga de delimitar la única posesión de este hombre: su interior. "No te diré nunca cómo fui hundiéndome, día tras día, entre los hombres perdidos, ladrones y asesinos y mujeres que tienen la piel del rostro más áspero que cal agrietada" (p. 30).

Dicha oración resulta fundamental para brindar un panorama general del interlocutor, pues el tono negativo que emplea, sumado a la condición de perdición en la que manifiesta encontrarse ("...hace mucho tiempo que estoy perdido" (p. 30), trazan una línea de programación de la lectura que a continuación se presenta. Para Flores (1987), las primeras palabras del cuento desempeñan dos funciones determinantes a lo largo del relato:

Primero, sirve para ilustrar la polaridad y para sosener [sic] el distanciamiento y la tensión entre el mundo del narrador y el

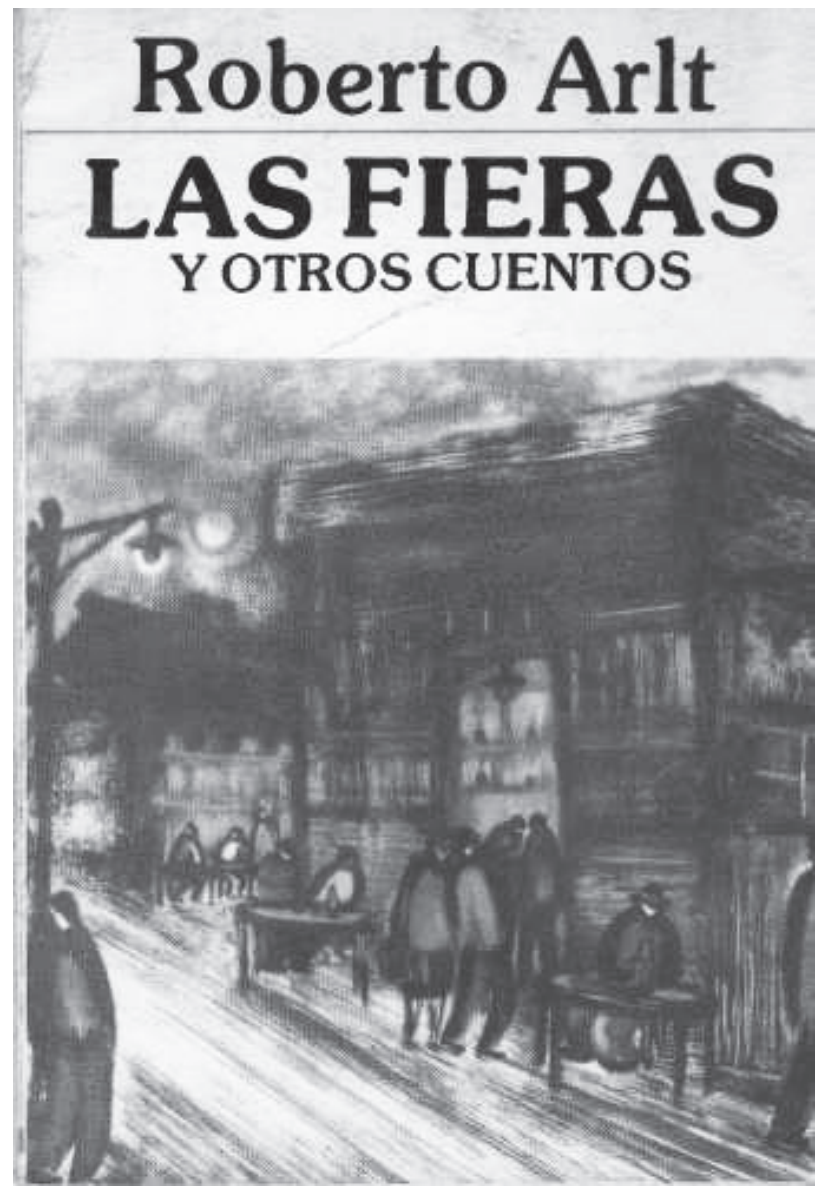

mundo que habita esa mujer incógnita a la que él le dirige la palabra — falsamente, por supuesto, en cuanto se trata de un monólogo. Segundo, forma parte del silencio, y lo refuerza, como uno de los elementos constitutivos de esa latitud sombría en la que se planta el narrador para recordar, desde allí, su tránsito de un mundo a otro; es decir, su caída, ese ir hundiéndose consciente y paulatinamente es su propio "proceso de descomposición". Puesto que el ámbito que se nos va dibujando es irremisiblemente incompatible con el de esa mujer desconocida a la que se pretende hablarle, el narrador va diciendo y negándolo todo al mismo tiempo.

De esta manera, inmediatamente se sitúa al público lector en la ciudad argentina de 1930, cuya efervescencia es evidente y está colmada de innovaciones tecnológicas, nuevas tendencias 
comerciales, modernos medios de transporte..., pero también se halla dividida en dos mundos distintos por completo, claramente separados en el cuento por la presencia del vidrio del bar donde está el protagonista. Dicho distanciamiento se hace más evidente a partir del nombre de dicho lugar: Ambos Mundos, lo cual es un importante indicador del carácter binario que se pretende presentar desde el inicio del relato: cortesía / grosería, civismo / violencia, dignidad / degradación, respetabilidad / animalidad, entre muchos otros.

Así, por un lado está la ciudad "normal", que busca florecer, adelantarse y estar a la altura de las grandes metrópolis europeas, modernas y cosmopolitas. Por otro lado se encuentra el sector más desprestigiado y olvidado por los habitantes de la ciudad "decente"; se trata de sitios no regidos por la mentalidad del progreso, el trabajo asalariado, las normas sociales de convivencia o alguna clase de aparato represivo.

Este último sector se halla conformado por personas que se encuentran por debajo de la clase social más baja, cuyos medios de sobrevivencia son, principalmente, actividades relacionadas con la delincuencia y la violencia; a este ignorado grupo se le denomina "lumpen", término que hace referencia al lumpenproletariado ${ }^{2}$. Asimismo, se les ha llamado en general "desclasados" a los integrantes de esta esfera, pues no cumplen con las características propias del proletariado urbano ni pueden ubicarse en la "normalidad" social, sino que, por el contrario, se hallan en un estado infrahumano. Tales personas son consideradas como desechos, porque sus hábitos no son precisamente los esperados para seres humanos productivos (trabajo, matrimonio, fuerza laboral) y, por lo tanto, no son de provecho para la sociedad (robos, prostitución, proxenetismo, asesinatos). Para Guerrero (1972), las características principales del lumpen son el aburrimiento y la ferocidad; asimismo, un rasgo que lo define es encontrarse fuera del orden pequeñoburgués establecido por la familia, el trabajo, la religión y demás instituciones:

Constituido desde la perspectiva pequeñoburguesa y no desde la experiencia vivida

2 El Diccionario de la Real Academia Española de 2016, define este término como la "capa social más baja y sin conciencia de clase". de sus miembros, el mundo lumpen es el trasfondo sobre el cual se mueve el personaje. Desclasarse y llegar a ser uno de sus miembros no solo es una posibilidad inscripta en su condición social sino, incluso, la que más le corresponde. En este mundo se niega la legalidad propia de su clase y se verifica su funcionamiento. El personaje contempla a sus miembros y alterna con ellos viviéndolos como si personificaran las distintas formas de la caída (Guerrero, 1972, p. 65).

Es por esto que en "Las fieras", la presencia del vidrio de la cantina en donde se encuentra el protagonista, tan sutil que podría pasar desapercibida, resulta fundamental para poner de manifiesto esta separación social entre miembros de una misma ciudad; desde un sitio alejado que se ignora desde afuera, los desclasados observan a las personas hacer su vida a escasos metros, como si se tratara de habitantes de dos mundos distintos (nuevamente la recurrencia al nombre del bar), lo cual queda debidamente esclarecido al final del relato:

Por la noche llegan perezosamente hasta la mesa de junto a la vidriera, se sientan, saludan de soslayo a la muchacha de la victrola, piden un café y en la posición que se han sentado permanecen horas y más horas, mirando con expresión desgarrada, por el vidrio, la gente que pasa (p. 35).

Aquí se pone de manifiesto uno de los principales rasgos de la literatura arltiana: la presencia de personajes alejados del paradigma social tradicional. Como reacción ante una ciudad en auge de civilización y con ideas cosmopolitas, el autor dedica su obra a retratar y presentar crudamente ese lado que incomoda a los defensores del progreso. De esta manera, Arlt se propone contrariar la forma racional de concebir la realidad de su época y más bien presenta la otra cara de esta, que es vista como irracional por la hegemonía dominante.

De acuerdo con lo anterior, el protagonista del cuento narra algunos escasos e incompletos detalles de lo que fue su vida dentro de la ciudad "decente", así como los acontecimientos que 
conforman su cotidianidad tras haber cruzado la frontera imaginaria representada por el vidrio de la cantina e ingresar en el lumpen. A lo largo del relato, el personaje muestra plena conciencia de que la entrada a esta otra realidad va de la mano con una renuncia absoluta de su yo anterior, pues se trata de un proceso paulatino que implica un cambio radical de vida, de identidad ("Incluso he cambiado de nombre"), y dejar atrás lo que antes le daba una posición en el mundo "real".

Si bien se conocen muy pocos datos concretos sobre la procedencia de este hombre, él mismo se encarga de mencionar algunos fragmentos de su realidad, la cual describe como un proceso de descomposición sin retorno ("Lo dificultoso es explicarte cómo fui hundiéndome día tras día", p. 31). Debido a que se trata del tema central de su monólogo, es posible unir una serie de ideas presentadas en desorden cronológico y narrativo, y a partir de ahí determinar que en su vida hubo un detonante que lo impulsó a atravesar la barrera imaginaria del vidrio e ingresar en el lumpen. Llama la atención que este hecho, desconocido para quien lee, sea llamado por el protagonista como "horrible pecado", lo cual pone de manifiesto la concepción religiosa de pecado mortal y podría ligarse a la transgresión de los preceptos religiosos o por lo menos propios del "buen ciudadano".

Ya fuera por culpabilidad o imposibilidad de permanecer dentro del círculo social al que inicialmente pertenecía (pues el enigma nunca es resuelto), el personaje toma la decisión de ingresar en el mundo de la otredad marginada y adoptar el estilo de vida de sus habitantes. Esto puede verse a manera de caída gradual cuyo efecto genera aislamiento y soledad en él: "No te diré cómo fui hundiéndome día tras día. Quizá ocurrió después del horrible pecado. La verdad es que fui quedando aislado" (p. 39). No obstante, resulta interesante que, si bien ha dejado de pertenecer al conjunto de ciudadanos "civilizados" (aunque en ocasiones lleguen a su mente recuerdos de su vida anterior), eso no necesariamente significa un rotundo acoplamiento al mundo del lumpen, pues desde allí manifiesta no sentirse por completo parte de él ni haberse convertido en "uno de ellos".
En ambos entornos, este hombre se halla invadido por la soledad y el aislamiento. En el primero de ellos se encuentra en una ciudad en crecimiento, llena de novedosos elementos materiales, pero aun así no logran satisfacerlo (esto resulta paradójico, pues una de las principales ideas del capitalismo es crear una sociedad de consumo que Ilene materialmente las necesidades de las personas): "Caminaba como antes por las calles, miraba los objetos que se exhiben en las vitrinas, y hasta me detenía sorprendido frente a ciertas ingeniosidades de la industria, mas la verdad es que estaba horriblemente solo" ( $p$. 39). Por otro lado, en el segundo entorno se halla rodeado de un grupo de personas que comparten una condición similar a la suya, lo cual no contribuye a crear una sensación de apoyo ni de pertenencia: "Pero a pesar de haberme mezclado con los de abajo, jamás hombre alguno ha vivido más aislado entre estas fieras que yo" (p. 31).

Ligado a lo anterior, este personaje es consciente de que ambos mundos (icónicamente representados en el texto por el protagonista y la mujer a quien se dirige) se encuentran muy cercanos, pero a la vez separados de manera tajante. En este sentido, la estrategia literaria de Roberto Arlt no permite que el público lector olvide uno de sus principales propósitos: destacar la doble cara de una ciudad en apariencia próspera y con miras al fortalecimiento económico, cultural y social. Para el autor es importante rescatar el lado oculto que los altos estratos de la sociedad no se interesan en considerar, y al igual que el protagonista del relato, también decide ingresar en el lumpen y hablar desde ahí, con la voz de quienes no son tomados en cuenta y se limitan a permanecer vigilantes tras un vidrio:

Sin embargo, vivimos aquí en la misma ciudad, bajo idénticas estrellas. Con la diferencia, claro está, que yo exploto a una prostituta, tengo prontuario y moriré con las espaldas desfondadas a balazos mientras tú te casarás algún día con un empleado de banco o un subteniente de la reserva (p. 32).

Si bien estas personas se encuentran fuera de lo aceptado por la sociedad y llevan una existencia marginal, es importante mencionar que, con el paso del tiempo, ellas asimilan su condición y 
terminan por resignarse y aceptar el determinismo en el cual han caído sus vidas. Se debe aclarar que no es una decisión preconcebida ni se busca con un propósito específico, sino más bien -como le sucede al protagonista- se lleva a cabo un proceso de descenso social, o como lo llama Pastor (1979), un "proceso de aislamiento y ruptura progresiva" hasta llegar al límite de lo establecido. Esto implica reconocer su imposibilidad para volver a ser como antes y someterse a esa otra realidad. En el cuento, esto queda claro cuando el protagonista recuerda a la mujer, a quien asocia de inmediato con todo lo que ahora le resulta inalcanzable: "Y si me resta tu recuerdo es por representar posibilidades de vida que yo nunca podré vivir. Es terrible, pero rubricado en ciertos declives de la existencia, no se escoge. Se acepta" (p. 32).

Por consiguiente, este hombre toma plena conciencia de su estado de alienación en medio de esa tajante división entre lo interior y lo exterior, espacios irreconciliables por naturaleza y más bien siempre puestos en contraste, como pares binarios que son. Como lo afirma Pastor (1979), "no resulta de un acto libre de elección sino de la aceptación pasiva de una fatalidad que se ve como ineludible, pero que es, en realidad, la última fase del proceso de repliegue iniciado mucho antes" (p. 89). Así las cosas, cabe mencionar que la entrada en el lumpen no constituye un escape o remedio para los problemas de la vida anterior; más bien se trata de una alternativa sin retorno con la cual las personas dejan de ser alguien en el mundo "decente" y se sumergen en un abismo fatal que no representa ningún progreso, solo desintegración: "Ahora cada uno de nosotros lleva un recuerdo terrible que es una bazofia de tristeza. Ayer... hoy... mañana..." (p. 38).

Según Pastor (1979):

El personaje busca efectivamente liberación y purificación a través de esa destrucción de la máscara pequeño-burguesa que implica su entrada en el lumpen. Sin embargo, no se refiere nunca a ese proceso de destrucción en términos positivos como liberación o purificación, sino en términos negativos que expresa el choque y la censura de una conciencia pequeño-burguesa ante una realidad feroz. Así la liberación propuesta se transforma, en el contacto real con el lumpen, en la conciencia de la propia degradación. El personaje, después del acto simbólico de iniciación que es la ruptura con la clase a través del robo, el crimen, o la destrucción de la vida de una mujer, no se encuentra liberado sino degradado. La ruptura se convierte en caída (p. 93).

En este punto es importante mencionar que el personaje del cuento no realiza ningún esfuerzo por mejorar su condición ni por salir de ese mundo; más bien el texto se halla impregnado de un tono de derrota, pues sabe que una vez entrado en el lumpen no hay regreso, solo se produce un deterioro progresivo permeado de aburrimiento, violencia y resignación; de hecho él llega a decir que forma parte de un engranaje perezoso que lo envuelve cada vez más y del cual no tiene ánimo de escapar. Esto concuerda con el criterio de Guerrero (1972), quien opina que "por permanecer sin cuestionar su funcionamiento dentro de una estructura social que se rige según los valores negados, el lumpen queda reducido a una vida sin sentido que la trascienda, encerrado en su propia finitud" (p. 66).

Me faltan fuerzas para escaparme a ese engranaje perezoso, que en la sucesión de las noches me sumerge más y más en la profundidad de un departamento prostibulario, donde otros espantosos aburridos como yo soportan entre los dedos una pantalla de naipes y mueven con desgano fichas negras o verdes, mientras que el tiempo cae con gotear de agua en el sucio pozal de nuestras almas.

Además de lo anterior, el protagonista reconoce cómo ese hundimiento se acrecienta con el tiempo y el peso de ese determinismo es mayor que la propia voluntad (aunque en ningún momento se haga mención de un deseo, ya sea pequeño o incesante, por salir de su condición), lo cual produce que la inmersión en el lumpen y las consecuencias que eso implica se vuelvan tan cotidianas para él que ya ni siquiera eso funciona como aliciente para intentar un cambio: "A medida que pasan los años, cae sobre mi vida una pesada losa de 
inercia y acostumbramiento. La actitud más ruin y la situación más repugnante me parece natural y aceptable" (p. 31).

Así, y de acuerdo con el criterio de Guerrero (1972), "el mundo lumpen es, en definitiva, el lugar de la humillación absoluta. Los personajes de 'Las fieras' quedarán sumergidos en su dolor y su aburrimiento 'hasta el día que caigamos bajo el cuchillo...' porque el camino de la deshumanización no tiene retorno". Por lo tanto, lo único que va a acabar con la realidad de estos hombres es la muerte, que posiblemente llegará de forma violenta.

Por otra parte, es interesante notar la presencia de una importante polaridad que desempeña un rol determinante en el relato: sueños / realidad. El protagonista únicamente evoca su vida anterior en medio de momentos relacionados con el mundo de los sueños: vigilia, sonambulismo, sombra, recuerdos, inconsciencia. Así, los únicos episodios de escape a la realidad lumpen se producen de manera involuntaria, cuando aparecen el delirio y la confusión, y no es posible determinar en cuál de los dos mundos se encuentra.

"Una neblina de carbón flota permanente en este socavón de la infrahumanidad" (p. 31).

"Fue un martillazo en la sensibilidad. Nunca pude despierto imaginarme tu rostro con la nitidez que en la vorágine del delirio destacaba su relieve" (p. 33).

"Estalló tu recuerdo, una noche que tiritaba de fiebre arrojado al rincón de un calabozo". (p. 32).

Asimismo, con el transcurso del tiempo no solo los valores de la sociedad son transgredidos y olvidados, sino que la entrada en el lumpen y su correspondiente determinismo degradante también arrasan con facultades humanas elogiadas a nivel social. Por ejemplo, el protagonista lo externa al hacer referencia a su intelecto y sensibilidad, que han sido invadidos por las sombras y actitudes negativas: "Cómo explicar este fenómeno que deja libre la inteligencia, mientras los sentimientos embadurnados de inmundicia nos aplastan más y más en toda renunciación a la luz" (p. 38).
En uno de esos momentos breves, el personaje realiza un contraste entre ambos mundos y, de una manera resumida, aunque siempre fragmentada, pone de manifiesto lo que ha sido su vida. Además, exterioriza su condición infrahumana inmersa en una violencia vista como familiar. Mientras en el mundo exterior se encuentran presentes instituciones como bancos o la iglesia, y personas relacionadas con ellas, como el sacristán, en el mundo interior (casi subterráneo) se menciona la presencia de un revólver que genera un momentáneo sobresalto entre los que se encuentran en el bar.

Con base en lo anterior, es posible establecer que él invierte roles y pasa de ser un "ciudadano normal" a una bestia del lumpen: completamente contrario a lo que una vez fue. Como bien apunta Pastor (1979), "para el personaje, el lumpen representa la negación de la propia clase. Siguiendo un principio de inversión, se articula en torno a una serie de elementos que son el inverso de los que caracterizaban el ámbito de la pequeño-burguesía" (p. 90):

Muchas veces acude tu nombre a mis labios. Recuerdo la tarde cuando estuvimos juntos, en la iglesia de Nueva Pompeya. También me acuerdo del podenco del sacristán. Empinando el hocico y el paso tardo, cruzaba el mosaico del templo por entre la fila de bancos... pero han pasado tantos cientos de días, que ahora me parece vivir en una ciudad profundísima, infinitamente abajo, sobre el nivel del mar. Una neblina de carbón flota permanente en este socavón de la infrahumanidad; de tanto en tanto chasquea el estampido de una pistola automática, y luego todos volvemos a nuestra postura primera, como si no hubiera ocurrido nada (pp. 31-32).

Así, Arlt presenta al público lector un relato poco convencional en el cual no existe una estructura tradicional de introducción, desarrollo y conclusión; por el contrario, los hechos narrados son muy pocos y se limitan a la descripción de hechos aislados, desordenados cronológicamente o pertenecientes a personajes ajenos al principal. Además, no se tiene certeza en relación con los nombres de los actantes (solamente se mencionan apodos), de 
sitios geográficos o del tiempo exacto transcurrido entre los diferentes acontecimientos (únicamente se dice que han pasado años). No obstante, aunque no se cuenta con elementos ordinariamente contundentes para la construcción de un cuento "normal", uno de los objetivos del autor sí llega a cumplirse, pues quien lee acompaña al protagonista en su hundimiento en las profundidades del mundo lumpen y es capaz de asomarse a ese ignorado lado citadino.

Un ejemplo de lo anterior se muestra en el párrafo de conclusión del texto, pues a pesar de que no propone ninguna solución (ya se sabe que no la hay) a la condición de los personajes, ni mucho menos revela pistas en relación con personalidades o hechos del pasado (lo cual resulta perfectamente coherente, pues el hermetismo constituye la esencia del protagonista), sí deja clara la binariedad social representada por el vidrio del bar, el determinismo, la soledad y el silencio de quienes se encuentran en el lado interior, así como el desinterés de los habitantes del exterior, caracterizados con adjetivos relacionados con la honradez, valor que ellos hace mucho tiempo han dejado de practicar, al igual que han hecho con muchos otros establecidos por la hegemonía dominante:

Por eso, cuando en el silencio que guardamos junto a la mesa de café, repiquetea el timbre del teléfono, un sobresalto nos mueve las cabezas, y si no es para nosotros, bajo las luces blancas, bermejas o azules, Uña de Oro bosteza y Guillermito el Ladrón barbota una injuria, y una negrura que ni las mismas calles más negras tienen en sus profundidades de barro, se nos entra a los ojos, mientras tras el espesor de la vidriera que da a la calle pasan mujeres honradas del brazo de hombres honrados (p. 46).

\section{SILENCIO: COMUNICACIÓN EN EL LUMPEN}

Si bien el protagonista de "Las fieras" es a la vez el narrador que en primera persona relata al público lector la totalidad de anécdotas, cavilaciones, descripciones y confesiones presentes en el texto, es fundamental retomar que dicho discurso corresponde a un monólogo, no a una conversación; esto constituye un importante indicador del comportamiento comunicativo predominante en el mundo lumpen. Así, este hombre decide confesar algunos aspectos de su vida pasada y presente pero, como se mencionó anteriormente, lo hace a la sombra de los recuerdos o en momentos en los cuales no está por completo consciente, siempre solitario y reflexionando en torno a su existencia, pero sin compartirlo con los demás hombres que lo rodean.

De esta forma es posible comprobar que en el mundo interior no existe la camaradería, complicidad, comprensión ni mucho menos la posibilidad de apertura sentimental, pues todas esas actitudes se encuentran sepultadas tras la renuncia de la vida anterior. Así, el personaje considera inútil hacer mención de lo que alguna vez fue, pues eso forma parte de ese pasado sin retorno del cual nadie va a mostrar la mínima empatía o solidaridad: "Jamás le he hablado a ninguno de mis compañeros de ti, ¿y para qué?" (p. 30). Por lo tanto, en medio de una realidad violenta, el hermetismo reinante en el mundo del lumpen provoca que lo único común entre estos hombres sea el silencio. De hecho, es interesante notar que el protagonista considere a ese vínculo invisible e impronunciable existente entre ellos como una especie de miserable amistad silenciosa. "Llegué así por descendimientos progresivos hasta la miseria de esta amistad silenciosa, en la que los infaltables son Uña de Oro, el Pibe Repoyo y el Relojero" (p. 40).

Como lo hacen de muchas otras formas, estos hombres transgresores de las normas sociales no encuentran sentido en mantener las mismas formas de comunicación del mundo exterior, y más bien han descubierto que pueden llenar un poco de sus vacíos con el silencio mantenidos por todos: “¿Para qué hablar? Si todo lo dice el silencio de sombras que entolda el bar amarillo, donde se inclinan las cabezas que ya no tienen esperanzas terrestres" (p. 39). En esta última cita es fundamental resaltar la división y relación del protagonista entre el mundo "terrenal" / externo y el mundo lumpen / interno, de cuya existencia siempre tiene plena certeza. Si bien cada habitante del lumpen posee un pasado que no le interesa compartir, así como un desolador presente, sí comparte su condición al mantener el misterio y la reserva: "y el silencio es el 
vaso comunicante por el cual nuestra pesadilla de aburrimiento y angustia pasa de alma a alma con roce oscuro" (p. 35).

Es fundamental tener en cuenta que el silencio también es una forma de comunicación, no es solamente la ausencia total del sonido oral, pues implica un sistema de interacción entre las personas, con base en el contexto en el que estas se ubiquen. En el caso de los hombres lumpen, el silencio posee significados que van más allá de negarse a pronunciar palabras, pues funciona como una especie de evasión o sosiego en medio del tormento que viven:

Cada uno de ellos ve en sí un misterio inexplicable, un nervio aún no clasificado, roto en el mecanismo de la voluntad. Esto los convierte en muñecos de cuerda relajada, y este relajamiento se traduce en el silencio que guardamos. Nadie aún lo ha observado, pero hay días que entre cuatro apenas si pronunciamos veinte palabras.

Ahora en la mesa del café, bajo las luces amarillas, blancas y azules, el silencio constituye un reposo. Tenemos necesidad de un poco de descanso, para que se asienten nuestras infamias calladas, nuestros crímenes flojos (p. 44).

Como señala Masotta (1982), "el silencio en ese sentido es como una tregua, un beneficio momentáneo que se hacen: callan para sentirse menos inmundos" (p. 26). Así, en el momento en que las palabras aparecen les recuerdan su calidad de rechazados; por eso prefieren mantener un estado de silencio en el cual todos conservan un sentido de igualdad. En la opinión de Guerrero (1972), "romper por un instante la homogeneidad del silencio es nombrar lo que los margina, afirmarse como condenados y constatar su caída en los actos que relatan" (p. 71):

Nos comunicamos con el silencio. Un silencio que se descarga en la mirada o en una inflexión de los labios respondiendo con un monosílabo a otro monosílabo. Cada uno de nosotros está sumergido en un pasado oscuro donde los ojos de tanto haber fijado, se han inmovilizado como los de cretinos que miran absurdamente un rincón sucio (p. 41).

Así las cosas, el silencio constituye una parte fundamental de la realidad lumpen, casi podría decirse que actúa como un submundo dentro de un submundo, pues en el instante en que los lumpen sumergidos logran desconectarse del dolor que cargan y entran en ese círculo de silencio (quizá el único círculo en el cual participan), dejan de ser marginados aunque afuera todo avance de la misma manera y ellos permanezcan del otro lado del vidrio:

La vida continúa siempre igual, adentro y afuera, y este silencio es una verdad, un intervalo donde descansa nuestra expectativa de una mala noticia, ya que es necesario aguardarla siempre, aguardarla siempre en el desconocido que entre inopinadamente al café o en el temblequeo de la campanilla del teléfono (p. 41).

No obstante, las únicas veces en las que estos hombres rompen su sagrado silencio lo hacen para dar cuenta de sus actos violentos o deshonestos, hacia mujeres $\mathrm{u}$ otros hombres, agresiones, asesinatos o robos ("Una alegría espantosa estalla en el interior de cada fiera, y siguiendo el impulso de una vanidad inexplicable, de un orgullo demoníaco, se habla..." (p. 42)). Dentro de esa misma manera "amistosa" en que se comunican mediante el silencio, también lo hacen al poner sobre la mesa -como si fuera uno de sus tantos juegos de cartas- el sinfín de atrocidades cometidas, ya sea en conjunto o individualmente, lejos o cerca del bar... Cuando salen del submundo del silencio es solo para alimentar el mundo lumpen con acciones en las cuales estos hombres se sienten identificados. Esto coincide con el planteamiento de Guerrero (1972), quien opina que solo pueden hablar de lo que renueva la separación con la sociedad: "Con el universo de significados establecidos asumen la condena social, ya que en su hablar se muestra la humillación de estos hombres: el mismo movimiento que los lleva a separarse de la sociedad les impone el juicio que esta hace recaer sobre ellos" (p. 71):

Si se habla es de cacerías de mujeres en el corazón de la ciudad, su persecución en 
los clandestinos de extramuros donde se ocultan; si se habla, es de riñas con bandas enemigas que las han raptado, de asaltos, de emboscadas, de robos, escalamientos y fracturas. Si se habla es de viajes en transportes nacionales a "la tierra", si se habla es de la cárcel, de las eternas noches en la "berlina" (calabozo triangular donde el detenido no puede acostarse ni sentarse), si se habla es de los procedimientos de los jueces, de los políticos a quienes están vendidos, de los pesquisas y sus ferocidades, de interrogatorios, careos, indagatorias $y$ reconstrucciones, si se habla es de castigos, dolores, torturas, golpes sobre el rostro, puñetazos en el estómago, retorcimiento de testículos, puntapiés en las tibias, dedos prensados, manos retorcidas, flagelaciones con la goma, martillazo con la culata del revólver... si se habla es de mujeres asesinadas, robadas, fugitivas, apaleadas...

Siempre los mismos temas: el crimen, la venalidad, el castigo, la traición, la ferocidad (pp. 42-43).

\section{FIERAS: DESPOJO DE LA MÁSCARA}

A lo largo de la historia, la sociedad ha estado regida por un sistema basado en el establecimiento de pares binarios, los cuales han fungido como determinantes de una jerarquía en cuanto a la posición que ocupa cada uno de los elementos del par. De esta manera, es posible señalar que prácticamente todos los ámbitos se hallan atravesados por esta construcción, entre ellos: derecha/izquierda, hombre/mujer, arriba/abajo, fuerte/débil, superioridad/ debilidad, admisión/exclusión. Por lo tanto, se ha privilegiado solamente a uno de esos elementos y se ha denigrado y marginado al otro, al cual se le atribuyen características negativas y de inferioridad.

Como se mencionó anteriormente, "Las fieras" es un relato en el cual se intenta mostrar una construcción cercana a la realidad urbana de los años treinta. Por dicha razón, la binariedad es uno de los ejes principales que lo atraviesan, y las múltiples aristas que lo conforman se componen por distintos pares que se conjugan para actuar como una representación de la sociedad. Así, se hallan presentes oposiciones como matrimonio / prostitución, ciudad / lumpen, virtud / marginalidad, interior / exterior, lenguaje / silencio..., a partir de las cuales se logra mostrar un poco de aquellos elementos ubicados en el lado menos importante del par, y que son considerados marginados, desprovistos de todo viso de autoridad o reconocimiento. De acuerdo con el argumento de Pastor (1979):

La entrada al lumpen se apoya sobre la transgresión, y es la transgresión de los valores pequeño-burgueses lo que articula todo el sistema de valores del lumpen. Para entrar al lumpen, el hombre debe transgredir alguno de los valores centrales de la clase a los que atentan el robo, el crimen y la prostitución. A partir de la ruptura que marca su iniciación, el personaje entrado al lumpen participará de un sistema de valores que se define por simple inversión de los valores de clase, dando lugar a una serie de oposiciones binarias que a la vez separan y relacionan de manera inequívoca lumpen y pequeño-burguesía (p. 90).

Uno de los fundamentales es la oposición respeto / delito: el conjunto de normas básicas establecidas por la hegemonía dominante tiene como principal propósito mantener la máxima armonía posible entre las personas; de esta manera, quienes estén dispuestos a seguirlas se encontrarán en el lado positivo del par, mientras que quienes las desafíen serán considerados como seres negativos ubicados del lado marginado. Dicha normativa, al igual que las demás, produce una tajante división entre los individuos (así como nuevas oposiciones) y va ligada a la construcción social que se ha hecho sobre la cultura. Así, según Josefina Ludmer (1999),

(...) el delito funciona como una frontera cultural que separa la cultura de la no cultura, que funda culturas, y que también separa líneas en el interior de una cultura. Sirve para trazar límites, diferenciar y excluir. Con el delito se construyen conciencias culpables y fábulas de fundación y de identidad cultural (p. 14). 
En Las fieras, esta distinción resulta sumamente clara gracias a la presencia del ya mencionado vidrio del bar Ambos Mundos: de nuevo, la oposición interior / exterior es equivalente a delito / respeto, fieras / hombres, rechazo / aceptación, barbarie / civilización. Si bien la concepción de delito varía de acuerdo con su respectivo contexto, a lo largo de los siglos la transgresión de las normas socialmente instauradas implica un castigo, ya sea físico, reclusión en una cárcel, marginación e incluso la muerte. Siempre se ha buscado apartar a quienes han contrariado lo establecido, lo cual muchas veces acarrea la expulsión de dichos individuos hacia círculos sociales marginales y la división tajante entre miembros de una misma colectividad.

En el caso de los hombres lumpen hay un paso adicional, pues no solamente reciben el castigo de la marginalidad por haber cometido crímenes, sino que el comportamiento que desarrollan, sobre todo el relacionado con la predilección por el silencio y la violencia, produce la paulatina transición de hombre a fiera. Para Pastor (1979), "el lumpen no es un hombre degradado sino alguien que, a través de un proceso determinado, ha dejado de ser hombre en absoluto y se ha convertido en algo cualitativamente distinto" (p. 94). Así, en primer lugar, la decisión de rechazar por completo el lenguaje oral entre compañeros y comunicarse mediante el silencio constituye un gran acto de ruptura con respecto a las normas establecidas como "normales" para los seres humanos, quienes "por naturaleza" tienen la capacidad para interactuar con las demás personas al hablar y manifestarse por medio de la palabra dicha.

Por consiguiente, en el momento en que ellos -aunque lo hagan sin un acuerdo previo, al estilo típico de las convenciones sociales- dejan de lado una cualidad propia de la condición humana que, dentro de la perspectiva tradicional, resulta fundamental para la convivencia social y la manifestación de las diversas necesidades, también renuncian a uno de los lazos más importantes con el mundo exterior; por eso poco a poco van perdiendo su condición de hombres ("En el fondo de los ojos de estos ex hombres se diluye una niebla gris" (p. 35)) y se transforman en otros seres denominados "fieras", que emplean otra manera para comunicarse con sus semejantes y se acercan más a la forma de convivencia de las bestias. Guerrero (1972) señala:

Pero el pasado es irrecuperable porque el pasaje de hombre a "fiera" no puede ser nombrado por los lumpen; el lenguaje y la facultad de estructurar un sentido del mundo no les pertenecen: las "fieras" quedan enclaustradas en un ámbito sin significados propios. La falta de comunicación verbal de los lumpen en el café traduce esta pérdida de lo humano, de lo que por humano entiende la moral pequeño-burguesa; quienes la abandonan se excluyen de sus significados y ya no pueden saber cómo dejaron de pertenecer al universo del lenguaje, ni hacer inteligible la relación que los une. No les queda sino permanecer uno al lado del otro reconociéndose como ex hombres. Este reconocimiento mutuo entre iguales se expresa en el silencio (p. 70).

En segundo lugar, el comportamiento de los hombres lumpen, así como el entorno general en el que se desenvuelven, se ubica dentro del círculo de la más cruel violencia y actos rudos. Nuevamente, la hegemonía dominante promueve la vida pacífica y apegada a conductas de urbanidad como la cortesía o la honestidad; por lo tanto, es posible evidenciar una total oposición al esquema tradicional establecido como "correcto", la cual implica un actuar imprudente y atrevido, crueldad desmedida, completo desinterés por su entorno inmediato y lejano.

Así las cosas, otro de los pasos para la transformación dehombrea fiera es su actuar bárbaro, prácticamente animalizado, pues no es propio de los seres humanos "racionales" o considerados como buenos ciudadanos. Por eso abunda la mención de actos donde no media la razón o la consideración hacia la otredad, sino más bien los impulsos libres de toda contención por parte de algún mecanismo represor. Con base en lo anterior se puede decir que en el mundo lumpen no hay nociones sobre lo correcto o los pecados, pues su cotidianidad se relaciona con la explotación y violencia. Según Pastor (1979), "el espacio del lumpen será sencillamente un mundo sin sala, sin tregua, en el que la sordidez, violencia, agresión y explotación se aceptan y presentan como 
la única realidad sin mitificaciones ni apariencias que la mitiguen" (p. 91).

En este punto es interesante el planteamiento que hace Guerrero (1972), pues menciona que en el mundo exterior, la gran capa representada por toda la ideología dominante (valores o leyes, por ejemplo) cae sobre sus habitantes y les impide dar rienda suelta a sus deseos más profundos (que también están relacionados con el desprecio hacia los otros, el aburrimiento y la oposición hacia las normas impuestas). A eso se debe que el comportamiento bestial no se haga presente en todo momento, como en el mundo lumpen, pero sí está intrínseco en los seres humanos; por eso deben recurrir a una máscara bajo la cual esconden su verdadero sentir. Por otro lado, en el mundo lumpen esa máscara está completamente desechada (y con ella, como ya se mencionó, el respeto hacia todo tipo de autoridad) y sus miembros actúan de acuerdo con su propia voluntad o sus intereses inmediatos, individuales. De hecho, Pastor (1979) opina de una manera similar, al expresar que "el mundo del lumpen, pues, no sólo es dependiente del mundo pequeño-burgués, sobre el que se proyecta como un reflejo, sino que es idéntico a él en todo menos una cosa: la máscara" (p. 91).

De este modo, la hipocresía y falsedad que implica el uso de la máscara son desplazadas por un comportamiento considerado irracional por el lado externo, puesto que únicamente se apega a deseos y no a la sensatez promovida por el sistema hegemónico; de ahí que se hable de aceptación de la propia condición de fiera. Por tal razón Guerrero (1972) opina que el protagonista:

En el mundo lumpen ve, entonces, la realidad de su clase tal como sería, despojada del comercio hipócrita con lo ideológico: un orden regido por las pasiones y los apetitos egoístas. Pero en él se acepta sin enmascaramiento la realidad, y la conducta más valiosa es la que se adecua mejor a ella (p. 67).

Por otra parte, las descripciones que el personaje realiza de sus compañeros lumpen poseen un tono de animalización, y cada vez que se refiere a cada uno de ellos los compara con seres o animales primitivos caracterizados por ser salvajes o con comportamiento brutal y sangriento. De esta manera, su percepción de quienes se encuentran a su alrededor no posee rasgos de humanidad alguna; al contrario, cada vez se van pareciendo más a las bestias en las que poco a poco se han convertido (los subrayados son propios):

"Cipriano, como un yacaré [subrayado añadido] que sueña con la manigua" (p. 36).

"Estos hombres tenían la piel del cogote más roja que el colodrillo de los pavos [subrayado añadido]" (p. 36).

"Y sin embargo sonríe con la ingenuidad de un monstruo jovial [subrayado añadido]" (p. 37).

"sonríe con dulzura de hipopótamo resoplando agua y barro [subrayado añadido] en el cañaveral de una manigua" (Arlt, año, p.).

"Como un cocodrilo adormilado [subrayado añadido] en la marisma, apetece la inmundicia" (p. 37).

Incluso él mismo se coloca en ese grupo de seres casi monstruosos que cada vez tienen menos lazos con la humanidad exterior y lo que socialmente los caracteriza, como la capacidad para entablar relaciones con los demás (la creencia impuesta es que "por naturaleza, el ser humano es un ser social"), manifestar sus emociones, actuar con prudencia y valores, y procurar el bien de las otras personas. Por el contrario, aunque este personaje sabe que no se ha acoplado por completo a esos seres, sí se autodenomina fiera y reconoce en él las características propias del lumpen: ferocidad y aburrimiento: "Fieras enjauladas, permanecemos tras los barrotes de los pensamientos residuos, y por eso es que la sonrisa canalla se despega tan dificultosamente del semblante encolado en una contracción de aburrimiento perrero" (p. 39). Él ha asimilado totalmente su condición de fiera y las conductas propias de ella; por eso no aparece como una voz narrativa que juzga el comportamiento de los demás y se excluye del grupo: más bien se sabe capaz de incurrir en las mismas atrocidades y de sentir los mismos conflictos internos que atormentan a los otros hombres: 
Relatos de esta índole son frecuentes, pero para qué criticar las ferocidades inútiles. Todos estamos conscientes que en un momento dado de nuestras vidas, por aburrimiento o angustia, seremos capaces de cometer un acto infinitamente más bellaco que el que no condenamos. A decir la verdad, aploma a nuestras conciencias un sentimiento implacable, quizá la misma fiera voluntad que encrespa a las bestias carniceras en sus cubiles de los bosques y las montañas (p. 44).

\section{MUJERES DEL LUMPEN: LAS ALIENADAS DE LOS ALIENADOS}

A pesar de que la receptora ausente del monólogo del protagonista es claramente una mujer, y que a lo largo de todo el texto sea fundamental la presencia femenina, es necesario aclarar que las mujeres únicamente aparecen para fungir como personajes no solo secundarios, sino víctimas fatales de las fieras: no se les brinda la oportunidad de hablar o expresar alguna emoción; actúan como un escape momentáneo para esos hombres que ya no tienen nada en sus vidas, y lo único que les resta es desahogar su ira, impotencia y angustia en estos seres sumisos y resignados a vivir en un lugar que podría denominarse mundo sublumpen.

Tras haber explorado algunos aspectos fundamentales del mundo lumpen, se establece que el descenso desde el mundo exterior también constituye una especie de iniciación que implica cumplir ciertas condiciones; sin embargo, la que se menciona con más claridad en el relato y se repite constantemente es la agresión hacia las mujeres: golpes ocasionales, golpizas brutales, humillaciones de diversa índole, explotación, doblegamiento sexual y denigración total de sus vidas. Una vez más, esta conducta se opone de manera radical a la normativa tradicional del matrimonio y la convivencia armoniosa entre los cónyuges. Más bien aparece como un acto que todos han realizado y que, si bien no lo exhiben como un trofeo generador de orgullo, sí se menciona como algo común que los une, así como sucede con el silencio: "De un modo o de otro hemos robado, algunos han Ilegado hasta el crimen; todos, sin excepción, han destruido la vida de una mujer" (p. 35).
Dentro de la violencia salvaje antes descrita como característica típica de los habitantes de este mundo interior, la descarga de furia en contra de las mujeres es un acto cotidiano que no implica culpas ni arrepentimientos ("Cuando recuerda las mujeres que castigó, sonríe con dulzura de hipopótamo resoplando agua y barro en el cañaveral de una manigua" (p. 36)), más bien se ve como un pasatiempo al cual se dedican para no sentirse tan aburridos y a la vez saciar un poco del dolor que cargan:

(...) ¡ah! cómo explicar esta desesperación, nos lanzamos a la calle, vamos hacia los departamentos donde nunca falta una atorranta con la cual acostarse, y desfogar babeando en un mal sueño este dolor que no se sabe de dónde viene ni para qué. $Y$ es que todos llevamos adentro un aburrimiento horrible, una mala palabra retenida, un golpe que no sabe dónde descargarse ( $p$. 42).

La condición miserable de estas mujeres no distingue estado civil, edad, ocupación, salud o alguna otra categoría que pueda salvarlas del abismo donde se encuentran; tal y como ocurre con los habitantes del lumpen, ellas cada vez se van hundiendo más en su condición infernal y están determinadas a continuar en esas circunstancias hasta el final de sus días. Ya sean esposas, amantes, compañeras casuales o la cantinera del bar, no son amadas ni respetadas, sino que deben soportar todo tipo de dolor físico y psicológico, sin posibilidad de reclamar o manifestar desacuerdo frente a dichas situaciones, pues muchas veces el sustento propio o de sus familias depende de ese dolor:

(...) y en los rincones negras sosteniendo con un brazo a un recién nacido a quien amamanta con un pecho, mientras que para no perder tiempo con la mano libre le desprendían los pantalones a un ebrio rijoso (p. 34).

De vez en cuando le suministra a su "señora" una paliza brutal, y si Guillermito el Ladrón le pregunta por qué le pega, el Relojero se encoge de hombros, sonríe dolorosamente 
y contesta después de rumiar largo rato su respuesta:

-Qué sé yo. Será porque estoy aburrido (p. 40).

Ella quería irse a vivir con él, y Uña le preguntó si estaba dispuesta a darle una prueba de amor, y cuando la meretriz le preguntó en qué consistía la prueba de amor, él le contestó: dejarse atravesar la mano con un cuchillo, y como ella accedió, le clavó la mano en la tabla de la mesa (p. 44).

Entonces las miradas recorren las mesas próximas, se detienen en la muchacha que atiende la victrola, estalla un comentario breve y cruel como un petardo, una sonrisa fría encrespa algún labio, ya que se sabe con quién está por caer la desgraciada, incluso el que la ronda ya ha anticipado el número de palizas que le suministrará ( $p$. 43; los subrayados son propios).

Dentro de ese grupo de desgraciadas resulta interesante la presencia de Tacuara, la prostituta a quien el protagonista explota y lleva por muchos lugares para sacar provecho de ella. Sin embargo, a pesar de aparecer como una mercancía que trasladan de un lado a otro para satisfacer por instantes a un grupo de desconocidos, y también como una especie de bestia utilizada hasta que no es posible obtener nada de ella, es la única persona que posee conocimiento acerca del pasado del protagonista e intuye cuando la melancolía se apodera de él por medio de los recuerdos, p.e., "La única informada de tu existencia es Tacuara" (p. 30). Y también:

A veces pasa tu recuerdo por mi memoria como una estrella de siete puntas, y Tacuara como si adivinara tu tránsito celeste por mi vida, me examina rápidamente de pies a cabeza y me dice como si ella fuera mi igual [subrayado añadido]:

-¿Qué te pasa? ¿Te duele el corazón? (p. 39).

En la cita anterior se demuestra que el personaje ha depositado en ella lo más resguardado por él: su vida anterior, el horrible pecado y todos los secretos que lo llevaron a hundirse en el mundo lumpen. Él ve en Tacuara a una especie de mascota a quien puede externarle algunos fragmentos de su interior; ella es un ser insignificante-no representa nada para él一, por eso la considera inferior. Tampoco le da importancia al hecho de que ella le haga preguntas relacionadas con sentimientos o hechos del pasado, ni le interesa que tenga conocimiento sobre ellos, pues no forma parte de la amistad silenciosa. Esta mujer, como las otras, se caracteriza por ser débil y sufrir las violentas descargas de ira y aburrimiento por parte de las fieras. A pesar de ser un objeto de explotación, Tacuara mantiene su servilismo y sumisión ante el protagonista, incluso llega a preocuparse por los conflictos internos que él pueda tener.

Así las cosas, si las fieras son seres alienados, vacíos, que rechazan al mundo exterior y a su vez son rechazados por él, destinados a ser presa del aburrimiento y la ferocidad, las mujeres que los rodean aparecen como alienadas de esos alienados; si ellos son desclasados y ni siquiera son percibidos por la sociedad del mundo exterior, mucho menos va a haber preocupación alguna por lo que les suceda a estas mujeres:

Y es que todos Ilevamos adentro un aburrimiento horrible, una mala palabra retenida, un golpe que no sabe dónde descargarse, y si el Relojero la desencuaderna a puntapiés a su mujer, es porque en la noche sucia de su pieza, el alma le envasa un dolor que es como desazón de un nervio en un diente podrido (p. 42).

(...) lo cual no me impide sonreír cuando alguna de estas bestias la estropea a golpes a una de las desdichadas que lo mantiene, o comete una salvajada inútil, por el solo gusto de jactarse de haberla realizado ( $p$. $31)$.

Se recuerda entonces el placer rojo y terrible de aplastarle a puñetazos la cara a una mujer, o también el goce de bailar trenzados con una hembra esquiva en una milonga asesina, o también el primer dinero que nos dio la mujer que nos inició en la vida, 
billete de diez pesos que ella sacó de la liga y que nosotros recibimos con alegría temblorosa porque ese dinero lo había ganado acostándose con otros (p. 45).

\section{CONCLUSIONES}

La obra de Roberto Arlt, particular, desconocida, incomprendida, corrompida y posteriormente reconocida y admirada, posee un estilo innovador en múltiples aspectos, pues rechaza las formas tradicionales de hacer literatura, tanto a nivel estético como de estructura; de ahí que sea considerado un gran representante de la vanguardia literaria latinoamericana, al no presentar rasgos similares a otros autores, sino más bien desarrollar peculiaridades muy puntuales como el uso del lenguaje coloquial o la incorporación de temáticas no tratadas en la época, que lo convierten en único ante la crítica posterior y constituye una importante referencia para otros autores. Además, su propuesta posee una apropiación y una renovación de aspectos como el realismo o la ciudad, lo cual es típico de la vanguardia, pues si bien no crea algo de la nada, reinventa lo ya establecido y, con su estilo propio, se manifiesta en contra de lo canónico, considerado como natural o imposible de cambiar.

Por otro lado, es fundamental tener presente el lugar de enunciación desde el cual Arlt escribe: su origen humilde y las distintas vivencias que tuvo se convierten en las armas fundamentales para conformar un estilo literario único, tanto a nivel léxico como en el enfoque de los temas. Así, él mismo se atreve a acercarse al lumpen y hablar desde allí; no es pretencioso ni quiere escribir sobre asuntos de los que no sabe, sino más bien se centra en tratar aquellos con los cuales ha entrado en contacto a partir de las propias vivencias. Es por esta razón que tanto él como su obra no fueron bien recibidos dentro de los principales grupos literarios de la época, pues no se ajustaban a los parámetros conocidos hasta el momento. Arlt, como periodista de las "notas rojas", pudo conocer mejor aquellas situaciones desagradables sobre las cuales no se suele hablar y las traslada a sus obras a partir de distintas perspectivas; de esta manera es posible que fueran conocidos aquellos sectores ignorados por una sociedad donde, en teoría, solo había cabida para el auge económico y el cosmopolitismo.

El cuento "Las fieras" presenta una deconstrucción de la versión tradicional de la sociedad pequeño burguesa perteneciente a la ciudad de Buenos Aires en los años treinta. A pesar de que el desarrollo de las metrópolis y los impulsos tecnológicos acaparan la atención de los ciudadanos, y se busca el crecimiento socioeconómico con base en el ascenso en los principales círculos, Roberto Arlt decide mostrar la otra cara de este lugar donde, en apariencia, solo hay cabida para el progreso de sus habitantes. De esta manera, el escritor argentino se adelanta a postulados como los derridianos, que plantean ubicarse desde el núcleo mismo de la hegemonía para cuestionar, desmontar y desestabilizar lo que en primera instancia es percibido como normal por la sociedad, y por lo tanto no se suele poner en tela de juicio o de duda. Por eso se propone retratar el mundo lumpen desde el mismo interior del protagonista y plantea una serie de conflictos completamente ajenos para la sociedad pequeña burguesa que se halla del otro lado del vidrio.

En esta nueva realidad que encierra el relato es posible distinguir múltiples oposiciones que demarcan los límites de la sociedad: adentro / afuera, hombre / fiera, mujer / prostituta, casa (pequeño-burgués) / café (lumpen). De esta forma queda muy clara la división tajante entre los miembros de una misma sociedad; esto resulta sumamente excluyente y determinante en relación con los estilos de vida que deben llevar, así como en el destino que les espera.

En relación con el mundo lumpen, se produce una renuncia completa a las normas y valores propios de la sociedad (mundo exterior), los cuales aparecen como una máscara que les impide actuar de acuerdo con sus impulsos y deseos; por el contrario, las fieras se despojan de esas ataduras y desechan por completo la ideología dominante, pero a la vez ellos mismos son vistos como desechos por quienes se encuentran del otro lado del vidrio, incluso son ignorados por esas personas. Como rasgos principales de este mundo se encuentran el aburrimiento y la ferocidad; además, otro aspecto que los aleja más de la condición humana es emplear el silencio como medio de comunicación, 
Entre la ferocidad y el aburrimiento: Un acercamiento al cuento "Las Fieras", de Roberto Arlt

en lugar del lenguaje oral que se articula "por naturaleza", pues esto les sirve para evadir momentáneamente la condición infrahumana en la que se encuentran. Por otro lado, utilizan a las mujeres como mecanismo para descargar un poco de la ira que acumulan, pues son lo único que se encuentra más abajo que ellos y por eso se sienten con la potestad para actuar con violencia brutal. Por su parte, las mujeres están resignadas a su realidad y no oponen resistencia ante los ataques que reciben; más bien algunas manifiestan actitudes compasivas hacia las fieras.

En el caso del protagonista del cuento, el recuerdo y la inconsciencia lo alejan del mundo lumpen durante algunos instantes; por eso puede entrar en el monólogo confesional autocompasivo que construye el relato. Sin embargo, en cuanto regresa a su realidad miserable, continúa participando de las actividades violentas que la componen. Él entra en caos existencial cuando vuelve su memoria hacia el pasado y sale por un instante de su alienación, pero eso no implica arrepentimiento o deseo de volver a ser el de antes, lo cual ya sería imposible.

\section{REFERENCIAS BIBLIOGRÁFICAS}

Arlt, R. (1933). El jorobadito y otros cuentos. Argentina: Ediciones del Sur. Obtenido desde: http://biblio3.url. edu.gt/Libros/roberto/el-jorobadito.pdf
Bosi, A. (2002). La parábola de las vanguardias latinoamericanas. En: Schwartz, J. (2002) Las vanguardias latinoamericanas. Textos programáticos y críticos. Madrid: Cátedra.

Flores, L. (1987). El mundo marginal de Roberto Arlt. Confluencia, 3, 1, pp. 47-59.

Goloboff, M. (2000). Introducción del coordinador. En: Los siete locos - Los lanzallamas / Roberto Arlt: edición crítica, Mario Goloboff, coordinador, $1^{\circ}$ edición. Colección Archivos.

Guerrero, D. (1972). Roberto Arlt: el habitante solitario. Argentina: Granica editor.

Ludmer, J. (1999). El cuerpo del delito. Un manual. Argentina: Libros Perfil, S.A.

Masotta, O. (1982). Sexo y traición en Roberto Arlt. Argentina: Centro Editor de América Latina.

Pastor, B. (1979). Dialéctica de la alienación: ruptura y límites en el discurso narrativo de Roberto Arlt. Revista de crítica literaria latinoamericana, 10, 87-97.

Real Academia Española (2016) Diccionario de la lengua española ( $23^{\mathrm{a}}$ ed.) Obtenido desde: http://dle.rae. $\mathrm{es} /$ ?w=diccionario

Renaud, M. (2000). Los siete locos y los lanzallamas: audacia y candor del expresionismo. En: Arlt, R. (2000) Los siete locos - Los lanzallamas / Roberto Arlt: edición crítica, Mario Goloboff, coordinador, $1^{a}$ edición. Universidad de Costa Rica: Colección Archivos. 